\title{
Multicenter Retrospective Study of Secukinumab Drug Survival in Psoriasis Patients in a Daily Practice Setting: A Long-Term Experience in Spain
}

Esteban Daudén · Glauber Pacelli Gomes de Lima · Susana Armesto • Enrique Herrera-Acosta •

David Vidal · Eva Villarasa · Raquel Rivera · Pablo de la Cueva · Antonio Martorell · Ferran Ballesca •

Isabel Belinchón · Gregorio Carretero • Lourdes Rodríguez · Alberto Romero-Maté (D) · Josep Pujol-Montcusí • Laura Salgado · Antonio Sahuquillo-Torralba · Pablo Coto-Segura • Ofelia Baniandrés · Rosa Feltes •

Mercé Alsina · Mar Llamas-Velasco

Received: September 28, 2020 / Accepted: September 4, 2021 / Published online: September 24, 2021

(c) The Author(s) 2021

\section{ABSTRACT}

Introduction: There is limited and conflicting evidence over the real-world drug survival of secukinumab (SEC) in patients with psoriasis, especially in the long term. Our objective was to analyze the short- and long-term survival of SEC

E. Daudén $(\bowtie) \cdot$ G. P. G. de Lima •

M. Llamas-Velasco

Hospital Universitario de la Princesa, Calle de Diego de León, 62, 28006 Madrid, Spain

e-mail: estebandauden@gmail.com

S. Armesto

Hospital Universitario Marqués de Valdecilla,

Santander, Spain

E. Herrera-Acosta

Hospital Virgen de la Victoria, Málaga, Spain

D. Vidal

Hospital de Sant Joan Despí Moisés Broggi,

Barcelona, Spain

E. Villarasa

Hospital de la Santa Creu i Sant Pau, Barcelona, Spain

R. Rivera

Hospital Universitario 12 de Octubre, Madrid, Spain

P. de la Cueva

Hospital Universitario Infanta Leonor, Madrid, Spain
(S-SEC) and its predictive factors for the treatment of psoriasis.

Methods: Patients clinically diagnosed with plaque psoriasis and under treatment with secukinumab $(n=384)$ in a daily practice setting were analyzed in a retrospective, multicenter study performed in a nationwide cohort and followed up for a period of 2 years. Kaplan-Meier curve was plotted to analyze drug

\section{A. Martorell}

Hospital de Manises, Valencia, Spain

\section{F. Ballesca}

Hospital Universitario Germans Trias i Pujol,

Barcelona, Spain

I. Belinchón

Hospital General Universitario de Alicante ISABIAL, Alicante, Spain

G. Carretero

Hospital Universitario Doctor Negrín, Las Palmas de Gran Canaria, Spain

L. Rodríguez

Hospital Universitario Virgen del Rocío, Sevilla, Spain

\author{
A. Romero-Maté \\ Hospital de Fuenlabrada, Madrid, Spain \\ J. Pujol-Montcusí \\ Hospital Universitari "Joan XXIII", Tarragona, Spain
}


survival time, and log-rank test was performed to compare several groups. Factors related to speed of treatment discontinuation were studied with a Cox regression model.

Results: The overall cumulative secukinumab drug survival rates observed at $6,12,18$, and 24 months were $97.1 \%, 89.0 \%, 81.1 \%$, and $74.3 \%$, respectively. Obesity [hazard ratio (HR), 1.809 , CI 95\% 1.114-2.962; $p=0.004$ ] and previous experience with biological therapies, particularly those who had been treated with $\geq 2$ biologicals with different mechanisms of action (HR 3.476, CI 95\% 1.875-6.444; $p=0.017$ ) were associated with an early discontinuation, whereas psoriatic arthritis was associated with delayed discontinuation, (HR 0.493, CI 95\% 0.265-0.917; $p=0.025$ ).

Conclusions: In our study, we found that cumulative secukinumab drug survival for psoriasis patients for the period 6-18 months was in the range of real-world evidence studies. Additionally, we observed a relatively high long-term survival rate at 24 months (74.3\%).

Keywords: Anti IL-17; Drug survival; Psoriasis; Secukinumab

L. Salgado

Complejo Hospitalario Universitario, Pontevedra, Spain

\section{A. Sahuquillo-Torralba}

Hospital Universitario y PolitécnicoLa Fe, Instituto de Investigación Sanitária la Fe, Valencia, Spain

P. Coto-Segura

Hospital Vital Alvarez-Buylla de Mieres, Asturias, Spain

O. Baniandrés

Hospital General Universitario Gregorio Marañón, Madrid, Spain

R. Feltes

Hospital Universitario la Paz, Madrid, Spain

M. Alsina

Hospital Clínic i Provincial, Barcelona, Spain

\section{Key Summary Points}

To date, there is limited and conflicting evidence over the real-world drug survival of secukinumab in patients with psoriasis, especially in the long term.

The overall cumulative secukinumab drug survival rates observed at $6,12,18$, and 24 months were $97.1 \%, 89.0 \%, 81.1 \%$, and $74.3 \%$, respectively. Drug ineffectiveness was the main reason for discontinuation.

Obesity and previous experience with biological therapies, particularly those who had been treated with $\geq 2$ biologicals with different mechanisms of action, were associated with an early discontinuation, whereas psoriatic arthritis was associated with a higher persistence.

\section{INTRODUCTION}

Secukinumab (SEC) is a fully human monoclonal $\mathrm{IgG} 1 / \kappa$ isotype antibody that selectively binds to and neutralizes interleukin 17A (IL-17A), a proinflammatory cytokine with key involvement in the clinical manifestation of psoriasis [1]. Despite its high effectiveness and safety profile demonstrated in the treatment of moderateto-severe plaque psoriasis, there is limited and conflicting evidence over the real-world drug survival of secukinumab in patients with psoriasis [2-15], especially in the long term [16-18]. Moreover, there is also a great variability in the results related to the predictors of a greater or lesser survival. Our objective was to analyze the short- and long-term survival of SEC (S-SEC) and its predictive factors for the treatment of psoriasis in a retrospective, multicenter study performed in a nationwide cohort of psoriasis patients in Spain followed up for a period of 2 years. 


\section{METHODS}

The study was a collaboration between 20 Spanish hospitals following patients in an uncontrolled, daily practice cohort, non-interventional and observational manner between February 2014 and March 2018. It was approved by the Ethics Committee of Hospital La Princesa (EDT-SIA-2017-01), and written informed consents were obtained from patients.

As requirements of the study, the patients had been clinically diagnosed with plaque psoriasis and were under treatment with SEC in a daily practice setting. The subjects were followed up for a minimum of 3 months and a maximum of 24 months. Patients under concomitant treatment with systemic or topical antipsoriatic drugs were also included in the study.

In agreement with the officially approved regimen recommended for the treatment of plaque psoriasis with SEC, $300 \mathrm{mg}$ of the drug was subcutaneously administered to patients weekly during the first 4 weeks and then on a monthly basis. Cohort monitoring was performed immediately before beginning the treatment (baseline) and then at 1, 3, 6, 12, 18, and 24 months after the therapy start date.

Drug survival (roughly, the time from starting the treatment until drug withdrawal) was calculated by plotting Kaplan-Meier curves. Log-rank test was used to compare survival time of naïve versus biologically experienced patients, no obese patients [body mass index $\left.(\mathrm{BMI})<30 \mathrm{~kg} / \mathrm{m}^{2}\right]$ versus obese patients $\left(B M I \geq 30 \mathrm{~kg} / \mathrm{m}^{2}\right)$, and patients starting treatment with baseline Psoriasis Area Severity Index (PASI) $<10$ versus those who presented PASI $\geq 10$ at initial visit. Furthermore, Cox regression models were used to explore possible relation between SEC survival and several factors, including patient's gender, age, psoriasis evolution time, obesity (BMI $<30$ versus BMI $\geq 30 \mathrm{~kg} / \mathrm{m}^{2}$ ), presence of psoriatic arthritis, baseline PASI (PASI $\geq 10$ versus PASI $<10$ ), and concomitant treatment. Previous exposure to other biologic treatments was unfolded in two variables: number of prior biological treatments [naïve or single biological experienced versus multiexperienced ( $\geq 2$ prior biologicals)], and mechanism of action of biological experienced [none, anti-tumor necrosis factor (TNF), antiIL12/23, or both]. Hazard ratios (HR) with their 95\% confidence interval (CI) are shown, and $p$ values $<0.05$ were considered as significant. Analyses were performed with IBM SPSS package 23.0 (Armonk, NY, USA).

\section{RESULTS}

A total of 384 patients were included in the study (241 males and 143 females). Among those, $278(72.4 \%)$ started the study with a baseline PASI $\geq 10$ (median baseline PASI was $14.3 \pm 8.4)$. The mean age \pm standard deviation was $47.6 \pm 12.5$ years, and $30 \%$ of the patients presented psoriatic arthritis. Furthermore, $42.6 \%$ of the patients were obese (BMI $\geq 30$ ), and the total accumulated exposure time among the patients was 347.3 patient-years. The proportion of naïve patients and those who received $\geq 2$ biologics was $31 \%$ and $49 \%$, respectively.

The overall drug survival for secukinumab was analyzed using data from the 384 patients, of which $83(21.6 \%)$ discontinued the treatment at different moments of the study owing to drug ineffectiveness $(16.7 \%)$, side effects $(3.4 \%)$, or patient decision $(1.6 \%)$. The observed cumulative drug survival rate at $6,12,18$, and 24 months was $97.1 \%, 89.0 \%, 81.1 \%$, and $74.3 \%$, respectively (Fig. 1).

Survival rates for different groups were plotted and compared with log-rank test. Comparing survival rates for separate groups based on treatment history (Fig. 2A), we found that naïve patients were more likely to continue the treatment than patients who experienced other previous biologic treatments (log rank, $p=0.015)$. The cumulative S-SEC for bio-naïve patients at $6,12,18$, and 24 months was $97.5 \%$, $93.0 \%, 86.4 \%$, and $84.0 \%$ respectively, while S-SEC for bio-experienced patients was $96.9 \%$, $87.1 \%, 78.5 \%$, and $69.4 \%$, respectively.

We compared S-SEC between obese and nonobese patients (Fig. 2B), finding that shorter drug survival was associated with obesity (log rank, $p=0.004)$. The cumulative S-SEC for non- 
obese patients at $6,12,18$, and 24 months was $98.5 \%, 93.5 \%, 85.7 \%$, and $80.0 \%$, respectively. In contrast, patients with $\mathrm{BMI} \geq 30$ presented survival rates of $95.9 \%, 83.1 \%, 75.8 \%$, and $66.5 \%$ respectively. Additionally, no significant difference was found regarding drug survival rates between the group of patients who started with baseline PASI $\geq 10$ and those who started with PASI $<10$ (Fig. 2C).

The multivariate analysis of factors related to S-SEC (Table 1) showed that obesity (HR 1.809, CI $95 \% \quad 1.114-2.962 ; p=0.004)$ and prior experience with anti-TNF and anti-IL12/23 (HR 3.476, CI 95\% 1.875-6.444; $p=0.017$ ) were associated with a reduced S-SEC, whereas psoriatic arthritis was associated with increased S-SEC (HR 0.493, CI 95\% 0.265-0.917; $p=0.025$ ). The other variables analyzed (gender, age, psoriasis evolution time, baseline PASI $\geq 10$, and concomitant treatment) were not significantly associated with drug survival.

\section{DISCUSSION}

Although some real-world evidence (RWE) studies reporting the rates of S-SEC in psoriasis patients are available [2-15], scarce evidence about survival $\geq 2$ years has been collected
Fig. 2 Kaplan-Meier plots representing how drug survival relates to patient's treatment history (A), body mass index (B), or baseline PASI (C). Data show all-cause discontinuation

[16-20]. In most of the RWE studies included in two meta-analyses $[6,13]$, the patients were followed for a period shorter than 1 year. To the best of our knowledge, this is the second-largest RWE cohort study $(n=384)$ reporting S-SEC after 24-month follow-up. The reported results of S-SEC are very variable, probably because drug survival may be determined by multiple factors. The rates of overall survival that we have found at $6,12,18$, and 24 months, 97\%, $89 \%, 81 \%$, and $74 \%$ respectively, are consistent with those described in the meta-analysis (90\% and $80 \%$ at 6 and 12 months) [6], and remarkably higher than those previously reported by multicenter studies in the Netherlands [3] (76\% and $67 \%$ at 12 and 18 months) and in Denmark (45\% at 24 months) [19]. This discrepancy could be explained by the fact that the proportion of naïve patients in our study, 31\%, was higher than in Dutch or Danish studies, $17 \%$ and $21 \%$, respectively; and the proportion of patients

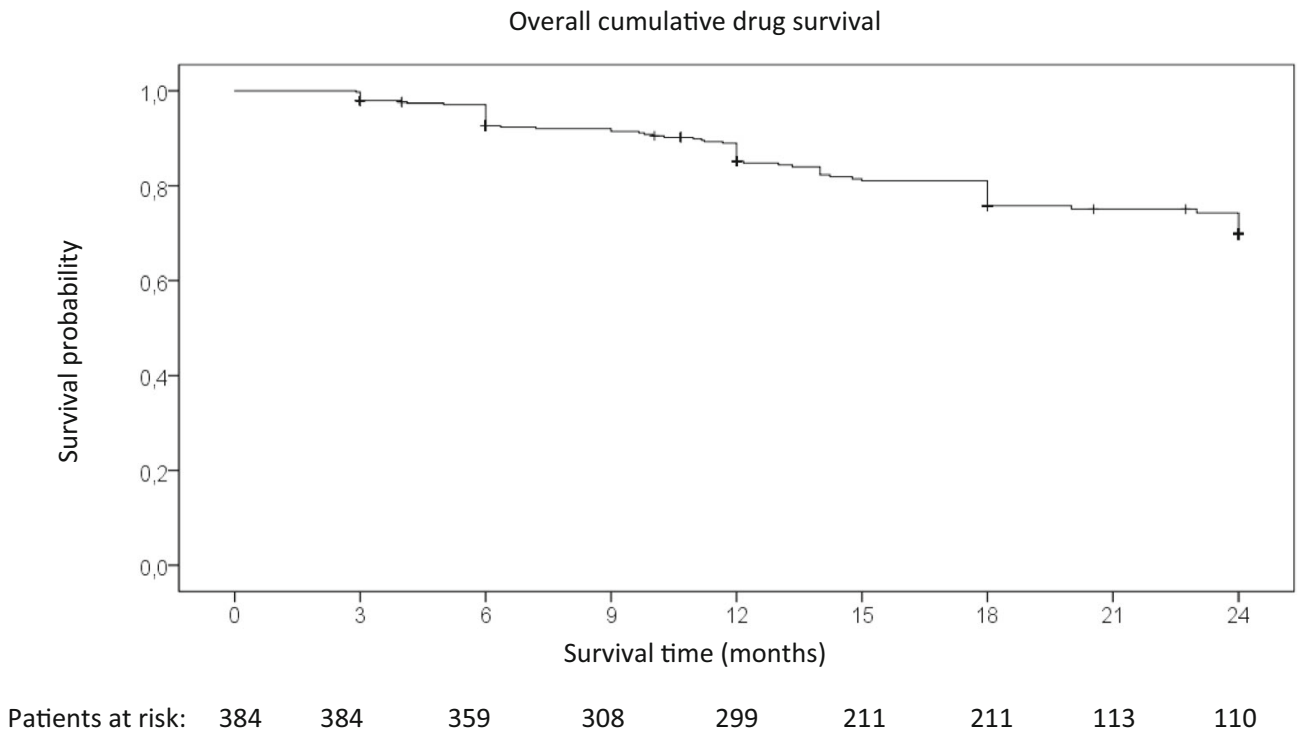

Fig. 1 Overall cumulative drug survival of secukinumab in psoriasis patients represented by Kaplan-Meier plot. Data show all-cause discontinuation 
A

Patients at risk:



Bio-naive

Bio-experienced

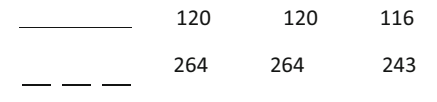

10399

76

$\begin{array}{lll}76 & 45 & 45\end{array}$

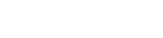

B

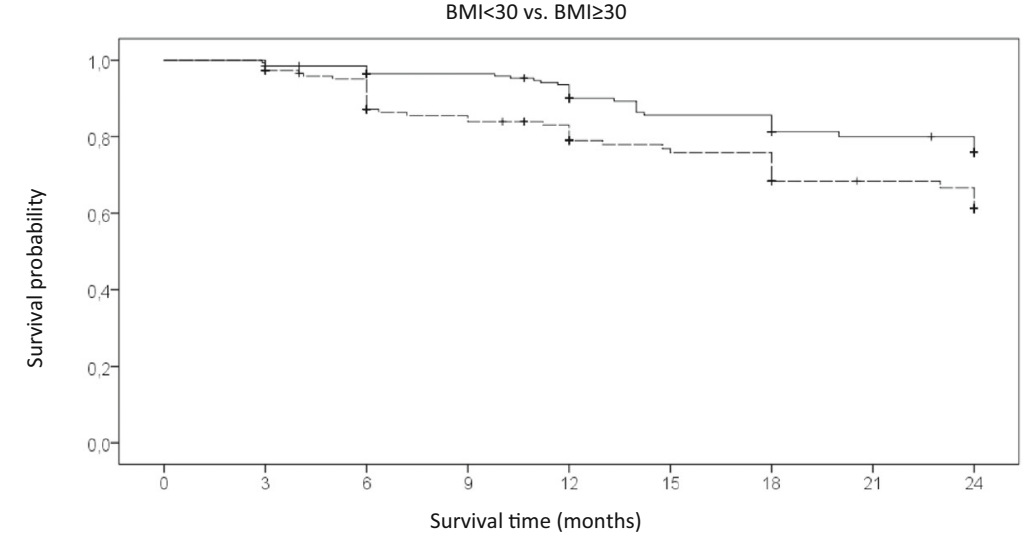

Patients at risk:

$\mathrm{BMI}<30$

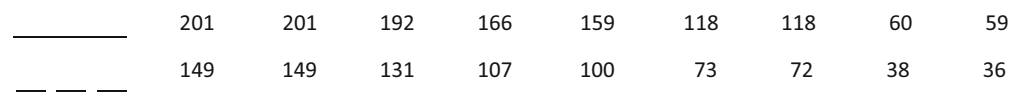

$B M I \geq 30$

$201-192$



C

Patients at risk:

Baseline PASI $\geq 10$

Baseline PASI $<10$

$$
\text { Baseline PASI } \geq 10 \text { vs. Baseline PASI }<10
$$

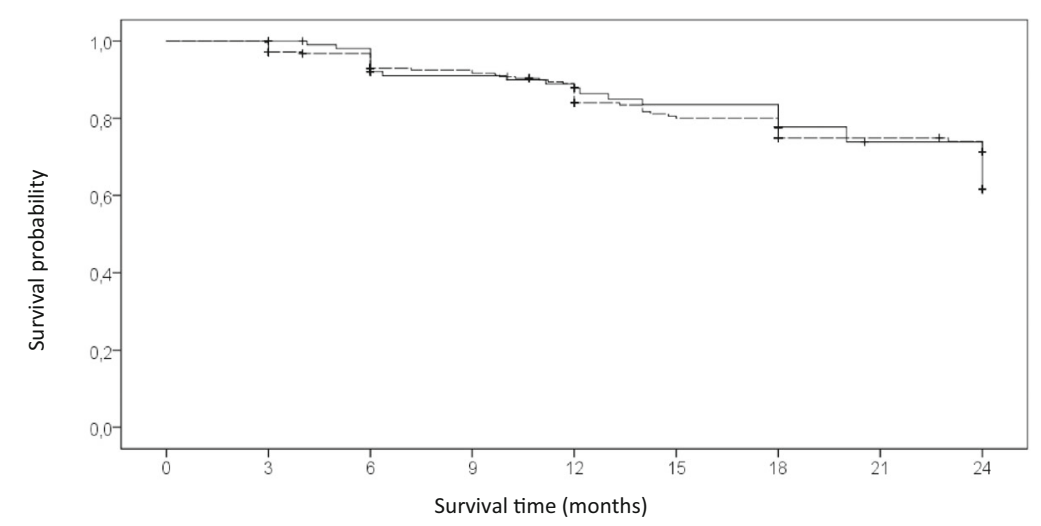

\begin{tabular}{|c|c|c|c|c|c|c|c|c|c|}
\hline & 278 & 278 & 259 & 219 & 211 & 149 & 149 & 92 & 89 \\
\hline & 106 & 106 & 100 & 89 & 88 & 62 & 62 & 21 & 21 \\
\hline
\end{tabular}


multiexperienced with two or more biologicals was lower in our study, $49 \%$, than in Dutch or Danish studies, $64 \%$ and $63 \%$, respectively $[3,19]$.

Although not universally confirmed, but consistent with most of the previous RWE studies, we have found that patients who presented obesity $[5,14]$ or were previously exposed to biologic treatments (versus naïve patients) $[3-5,7,10,11,14-16]$ showed an increased risk of discontinuing SEC. Moreover, in our study, patients who received two or more biologicals with different mechanisms of action before SEC discontinued treatment before naïve patients. On the contrary, in our study, coinciding with the case series by Yiu et al. [10], but in disagreement with other studies $[4,5,15,17]$, psoriatic arthritis was associated with a longer S-SEC.

Interestingly, no significant difference was found regarding drug survival rates between the group of patients who started with baseline PASI $\geq 10$ and those who started with PASI $<$ 10 , which is commonly overlooked in other drug survival studies in a real-world setting. On the other hand, in several studies it has been observed that the female gender was significantly associated with a poorer persistence $[3,12,14,15]$. This was not observed in our cohort of patients or in other studies $[4,5]$. The other variables analyzed (age, psoriasis evolution time, and concomitant treatment) were not significantly associated with S-SEC.

Limitations include the lack of assessment of deviations from the standard treatment regimen throughout the follow-up, and those derived from the multicenter and retrospective nature of the study. The influence on survival of difficult-to-treat localizations (nails, palms and soles, scalp) was not included in the analysis.

Table 1 Analysis of several factors that can potentially relate to drug survival (Cox regression model)

\begin{tabular}{|c|c|c|c|c|c|c|c|c|}
\hline \multirow{3}{*}{$\begin{array}{l}\text { Method } \\
\text { Variable }\end{array}$} & \multicolumn{4}{|c|}{ Forced introduction } & \multicolumn{4}{|c|}{ Forward stepway } \\
\hline & \multirow[t]{2}{*}{$p$} & \multirow[t]{2}{*}{ HR } & \multicolumn{2}{|c|}{ 95\% CI for HR } & \multirow[t]{2}{*}{$\bar{p}$} & \multirow[t]{2}{*}{ HR } & \multicolumn{2}{|c|}{ 95\% CI for $\mathrm{HR}$} \\
\hline & & & Lower & Upper & & & Lower & Upper \\
\hline Age & 0.330 & 1.012 & 0.988 & 1.035 & & & & \\
\hline Gender & 0.992 & 0.997 & 0.591 & 1.683 & & & & \\
\hline Obesity (ref. BMI < 30) & 0.035 & 1.734 & 1.038 & 2.896 & 0.019 & 1.809 & 1.104 & 2.962 \\
\hline Baseline PASI (ref. PASI $\geq 10$ ) & 0.842 & 1.059 & 0.605 & 1.853 & & & & \\
\hline Psoriasis evolution time & 0.250 & 0.985 & 0.961 & 1.010 & & & & \\
\hline Psoriatic arthritis & 0.010 & 0.430 & 0.226 & 0.818 & 0.025 & 0.493 & 0.265 & 0.917 \\
\hline BT type (ref. no BT) & 0.100 & & & & $<0.001$ & & & \\
\hline Anti TNF & 0.153 & 0.349 & 0.082 & 1.480 & 0.574 & 0.760 & 0.291 & 1.982 \\
\hline Anti IL12/23 & 0.613 & 1.392 & 0.386 & 5.018 & 0.503 & 1.533 & 0.439 & 5.357 \\
\hline Both & 0.976 & 0.976 & 0.196 & 4.855 & $<0.001$ & 3.476 & 1.875 & 6.444 \\
\hline Concomitant systemic treatment ${ }^{a}$ & 0.592 & 1.277 & 0.522 & 3.120 & & & & \\
\hline Previous BT (ref. 0-1) & 0.092 & 3.742 & 0.805 & 17.387 & & & & \\
\hline
\end{tabular}

$B M I$ body mass index, $B T$ biologic treatment, $C I$ confidence interval, $H R$ hazard ratio, $I L$ interleukin, PASI Psoriasis Area and Severity Index, ref reference, $T N F$ tumor necrosis factor

a Concomitant treatment: methotrexate, acitretin, leflunomide, steroids, nonsteroidal antiinflammatory drugs, or phototherapy 


\section{CONCLUSION}

In conclusion, in this multicenter, daily practice, nationwide, long-term study, we found that overall cumulative drug survival for SEC at 24 months was 74\%. Furthermore, obesity, previous exposure and multiexperience with two or more biological drugs with different mechanisms of action were associated with a higher risk for SEC withdrawal. Drug ineffectiveness and adverse events were the main reasons for drug discontinuation. This results provide valuable information in the context of daily clinical practice and may play a role in the clinical decision-making to choose the most appropriate biological.

\section{ACKNOWLEDGEMENTS}

The authors are grateful to Jesús Garrido for the statistical analysis and Manuel Gómez Gutiérrez and Cristina Santamaría for copyediting the manuscript.

Funding. No funding or sponsorship was received for this study or publication of this article. The Rapid Service Fee was funded by the authors.

Authorship. All named authors meet the International Committee of Medical Journal Editors (ICMJE) criteria for authorship for this article, take responsibility for the integrity of the work as a whole, and have given their approval for this version to be published.

Author Contributions. Dr. Esteban Daudén, Dr. Mar Llamas and Dr. Glauber lima were involved in data collection, study design, data analysis and writing of the manuscript. Dr. S. Armesto, Dr. E. Herrera-Acosta, Dr. D. Vidal, Dr. E. Vilarrasa, Dr. R. Rivera, Dr. P. de la Cueva, Dr. A. Martorell, Dr. F. Ballesca, Dr. I. Belinchón, Dr. G. Carretero, Dr. L. Rodríguez, Dr. A. Romero-Maté, Dr. J. Pujol-Montcusí, Dr. L. Salgado, Dr. A. Sahuquillo-Torralba, Dr. P. Coto-Segura, Dr. O. Baniandrés, Dr. R. Feltes and Dr. M. Alsina contributed to data collection, discussed the results and commented on the manuscript.

Disclosures. Dr. Esteban Dauden-Advisory Board member, consultant, grants, research support, participation in clinical trials, honorarium for speaking, research support, with the following pharmaceutical companies: Abbvie/ Abbott, Almirall, Amgen, Janssen-Cilag, Leo Pharma, Novartis, Pfizer, MSD-Schering-Plough, Celgene, Lilly and UCB. Lima, G.P.G has nothing to disclose. S. Armesto-honorarium for speaking Abbvie/Abbott, Almirall, Amgen, Janssen-Cilag, Leo Pharma, Novartis, and Lilly. E. Herrera-Acosta-Advisory Board member, consultant, grants, research support, participation in clinical trials, honorarium for speaking, research support, with the following pharmaceutical companies: Abbvie/Abbott, Almirall, Amgen, Janssen-Cilag, Leo Pharma, Novartis, Celgene, Lilly and UCB. Dr Vidal-Consultant and investigator for Abbvie, Janssen, Novartis, Celgene, Lilly and Leo. E. Vilarrasa-Advisory Board member, consultant, grants, research support, participation in clinical trials, honorarium for speaking, with the following pharmaceutical companies: Abbvie/Abbott, Almirall, Amgen, Celgene, Janssen-Cilag, Leo Pharma, Lilly, MSD-Schering-Plough, Novartis, Pfizer, and UCB. R. Rivera -Advisory Board member, consultant, grants, research support, participation in clinical trials, honorarium for speaking, research support, with the following pharmaceutical companies: Abbvie/Abbott, Almirall, Amgen, Celgene, Janssen-Cilag, Leo Pharma, Lilly, MSD-Schering-Plough, Novartis, Pfizer, and UCB. P. de la Cueva -Consultant, advisory board member, honorary for speaking and participation in clinical trials with the following pharmaceutical companies: Abbvie, Almirall, Astellas, Biogen, Boehringer, Celgene, Janssen., LEO Pharma, Lilly, MSD, Novartis, Pfizer, Roche, Sanofi, UCB not related with the submitted work. A. Martorell-Advisory Board member, consultant, participation in clinical trials, honorarium for speaking, with the following pharmaceutical companies: Abbvie, Almirall, Janssen-Cilag, Leo Pharma, Novartis, Pfizer, MSD, Celgene, Lilly and UCB. F. Ballesca-Personal fees from Leo Pharma, 
non-financial support from Novartis, non-financial support from ABBVIE, outside the submitted work. I. Belinchón-Acted as a consultant and/or speaker for and/or participated in clinical trials sponsored by the next companies: Janssen Pharmaceuticals Inc., Almirall SA, Lilly, AbbVie, Novartis, Celgene, Amgen, Leo-Pharma, Pfizer-Wyeth, UCB, and MSD. G. Carretero-Has served as a consultant for Abbvie, Janssen, MSD, and Pfizer; gave expert testimony for Abbott Laboratories, MSD, Pfizer, Janssen, Leo-Pharma, Novartis, Celgene, and Lilly; has participated as investigator in clinical trials of Abbvie, Janssen, MSD, Pfizer, Lilly, and Novartis; received grants from Abbvie, Janssen, MSD, and Pfizer and equipment from MSD and Pfizer. Dra L. Rodríguez-Served as a consultant and speaker for AbbVie Laboratories, Janssen Pharmaceuticals Inc, MSD, PfizerWyeth, Novartis, Celgene, Almirall SA, Lilly and Leo-Pharma. A. Romero-Maté-Has participated in Advisory Boards, consultant, participation in clinical trials, honorarium for speaking from Pfizer, Celgene, Novartis, UCB, Leo Pharma, Almirall and Lilly. J. Pujol-Montcusí-Has served as a consultant and/or paid speaker for and/or participated in clinical trials sponsored by companies that manufacture drugs used for the treatment of psoriasis, including AbbVie, Celgene, Janssen-Cilag, Almirall, Lilly, and Novartis. L. Salgado-Advisory Board member, consultant, grants, research support, participation in clinical trials, honorarium for speaking, research support, with the following pharmaceutical companies: Abbvie, Almirall, JanssenCilag, Leo Pharma, Novartis, Pfizer, MSDSchering-Plough, Celgene, Lilly. A. SahuquilloTorralba-Has served as a consultant and/or paid speaker for and/or participated in clinical trials sponsored by companies that manufacture drugs used for the treatment of psoriasis, including AbbVie, Celgene, Janssen-Cilag, LEO Pharma, Lilly, Novartis and Pfizer. P. Coto-Segura-Has participated in Advisory Boards or received grants, research support, honorarium for speaking from Abbvie, Janssen-Cilag, Novartis, Pfizer, Celgene, Lilly and UCB. O. Baniandrés-Has participated in Advisory Boards, consultant, participation in clinical trials, honorarium for speaking from Abbvie, Janssen-
Cilag, Pfizer, Celgene, Novartis, UCB, Leo Pharma, Almirall and Lilly. R. Feltes-Has participed in clinical trials for drugs development of Novartis, Lilly, UCB, Jannsen-Cilag, Almirall, Pfizer, Leo Pharma and Abbvie. M. Alsina-Advisory Board member, consultant, grants, research support, participation in clinical trials, honorarium for speaking, research support, with the following pharmaceutical companies: Abbvie/Abbott, Almirall, Amgen, Celgene, Janssen-Cilag, Leo Pharma, Lilly, MSD-Schering-Plough, Novartis, Pfizer, and UCB. M. Llamas-Advisory board member, consultant, research support, participation in clinical trials and honorary for speaking) with the following pharmaceutical companies: Abbvie, Almirall, Amgen, Boehringer, Celgene, Janssen, Leo,Lilly, Novartis, UCB, not related with the submitted work.

Compliance with Ethics Guidelines. The study design, data collection and analysis were approved by the Ethics Committee of H. Princesa (EDT-SIA-2017-01) Individually written informed consents were obtained from patients at the beginning of the study.

Data Availability. The data provided for the analysis and writing of this manuscript are available in an anonymized database accessible at Hospital Universitario de La Princesa (Madrid, Spain).

Open Access. This article is licensed under a Creative Commons Attribution-NonCommercial 4.0 International License, which permits any non-commercial use, sharing, adaptation, distribution and reproduction in any medium or format, as long as you give appropriate credit to the original author(s) and the source, provide a link to the Creative Commons licence, and indicate if changes were made. The images or other third party material in this article are included in the article's Creative Commons licence, unless indicated otherwise in a credit line to the material. If material is not included in the article's Creative Commons licence and your intended use is not permitted by statutory regulation or exceeds the permitted use, you will need to obtain permission directly from the 
copyright holder. To view a copy of this licence, visit http://creativecommons.org/licenses/by$\mathrm{nc} / 4.0 /$.

\section{REFERENCES}

1. Brembilla NC, Senra L, Boehncke W-H. The IL-17 family of cytokines in psoriasis: IL-17A and beyond. Front Immunol. 2018;9:1682.

2. Georgakopoulos JR, Ighani A, Phung M, Yeung J. Drug survival of secukinumab in real-world plaque psoriasis patients: a 52-week, multicenter, retrospective study. J Am Acad Dermatol. 2018;78: 1019-20.

3. Van den Reek JMPA, van Vugt LJ, van Doorn MBA, van der Kraaij GE, de Kort WJA, Lucker GPH, et al. Initial results of secukinumab drug survival in patients with psoriasis: a multicentre daily practice cohort study. Acta Derm Venereol. 2018;98:648-54.

4. Torres T, Balato A, Conrad C, Conti A, Dapavo P, Ferreira, , et al. Secukinumab drug survival in patients with psoriasis: a multicentre, real-world, retrospective study. J Am Acad Dermatol. 2019;81: 273-5.

5. Palacios-García L, Gómez de Castro C, Mir-Bonafé M, Calzon C, Galache C, Santos-Juanes J. Comment on "Secukinumab drug survival in patients with psoriasis: a multicenter, real-world, retrospective study." J Am Acad Dermatol. 2019;81:e81-2.

6. Augustin M, Jullien D, Martin A, Peralta C. Realworld evidence of secukinumab in psoriasis treatment-a meta-analysis of 43 studies. J Eur Acad Dermatol Venereol. 2020;34:1174-85.

7. Carpentieri A, Mascia P, Fornaro M, Beylot-Barry M, Taieb A, Foti C, et al. Effectiveness and safety of secukinumab in patients with moderate-severe psoriasis: a multicenter real-life study. Dermatol Ther. 2020;33:e14044.

8. Kishimoto M, Komine M, Kamiya K, Sugai J, Mieno M, Ohtsuki M. Drug survival of biologic agents for psoriatic patients in a real-world setting in Japan. J Dermatol. 2020;47:33-40.

9. Ohata C, Ohyama B, Katayama E, Nakama T. Realworld efficacy and safety of interleukin-17 inhibitors for psoriasis: a single-center experience. J Dermatol. 2020;47:405-8.

10. Yiu ZZN, Mason KJ, Hampton PJ, Reynolds NJ, Smith $\mathrm{CH}$, Lunt $\mathrm{M}$, et al. Drug survival of adalimumab, ustekinumab and secukinumab in patients with psoriasis: a prospective cohort study from the British Association of Dermatologists Biologics and Immunomodulators Register (BADBIR). Br J Dermatol. 2020;183:294-302.

11. Dapavo P, Siliquini N, Mastorino L, Avallone G, Merli M, Agostini A, et al. Efficacy, safety and drug survival of IL-23, IL-17 and TNF-alpha inhibitors for psoriasis treatment: a retrospective study. J Dermatol Treat. 2021;27:1-20.

12. Iznardo H, Vilarrasa E, López-Ferrer A, Puig L. Realworld drug survival of guselkumab, ixekizumab and secukinumab for psoriasis. Br J Dermatol. 2021. https://doi.org/10.1111/bjd.20416 (Online ahead of print).

13. Mourad AI, Gniadecki R. Biologic drug survival in psoriasis: a systematic review and comparative meta-analysis. Front Med (Lausanne). 2021;7: 625755.

14. Torres T, Puig L, Vender R, Lynde C, Piaserico S, Carrascosa JM, et al. Drug survival of IL-12/23, IL-17 and IL-23 inhibitors for psoriasis treatment: a retrospective multi-country, multicentric cohort study. Am J Clin Dermatol. 2021;22:567-79.

15. Graier T, Salmhofer W, Jonak C, Weger W, Kölli C, Gruber B, et al. Biologic drug survival rates in the era of anti-interleukin-17 antibodies: a time-periodadjusted registry analysis. Br J Dermatol. 2021;184: 1094-105.

16. Egeberg A, Bryld LE, Skov L. Drug survival of secukinumab and ixekizumab for moderate-to-severe plaque psoriasis. J Am Acad Dermatol. 2019;81: 173-8.

17. Chatzimichail G, Günther J, Ständer S, Thaçi D. Drug survival of secukinumab, ustekinumab, and certolizumab pegol in psoriasis: a 2-year, monocentric, retrospective study. J Dermatol Treat. 2021;11:1-5.

18. Egeberg A, Ottosen MB, Gniadecki R, et al. Safety, efficacy and drug survival of biologics and biosimilars for moderate-to-severe plaque psoriasis. $\mathrm{Br} \mathrm{J}$ Dermatol. 2018;178:509-19.

19. Ruiz-Villaverde R, Rodriguez-Fernandez-Freire L, Galán-Gutierrez M, Armario-Hita JC, Martinez-Pilar L. Drug survival, discontinuation rates, and safety profile of secukinumab in real-world patients: a 152-week, multicenter, retrospective study. Int J Dermatol. 2020;59:633-9.

20. Ruiz-Villaverde R, Rodríguez Fernández-Freire L, Galán-Gutiérrez M, Armario-Hita JC, Martinez-Pilar L. Secukinumab: drug survival in clinical practice settings. Actas Dermosifiliogr. 2021;112:361-4. 